\title{
Effects of regular salmeterol on lung function and exercise capacity in patients with chronic obstructive airways disease
}

\author{
A Grove, B J Lipworth, P Reid, R P Smith, L Ramage, C G Ingram, R J Jenkins, \\ J H Winter, D P Dhillon
}

\begin{abstract}
Background - The aim of this study was to evaluate the effects of single and chronic dosing with salmeterol on exercise capacity and lung function in patients with chronic obstructive pulmonary disease. Methods - Twenty nine patients of mean (SE) age 64 ( 1.5) years, forced expiratory volume in one second $\left(F E V_{1}\right) 42(3) \%$ of predicted, and 5-15\% reversibility to salbutamol $200 \mu \mathrm{g}$ were randomised to receive four weeks treatment with salmeterol $50 \mu \mathrm{g}$ twice daily or placebo in a double blind crossover fashion with a one week washout period in between. Measurements of spirometric parameters, static lung volumes, and exercise capacity were made one and six hours after a single dose, and six hours after the final dose of salmeterol or placebo.
\end{abstract}

Results - Salmeterol produced a small increase in $\mathrm{FEV}_{1}$ at one and six hours after a single dose, and this was maintained after chronic dosing (mean difference and 95\% CI versus placebo): single dosing at one hour $0.07(95 \%$ CI 0.02 to $0 \cdot 11) 1$, single dosing at six hours $0.16(95 \%$ CI 0.09 to 0.22$) 1$, chronic dosing at six hours $0 \cdot 11(95 \%$ CI 0.03 to 0.19$) 1$. The increase in forced vital capacity (FVC) was greater with salmeterol than with placebo six hours after single but not chronic dosing: single dosing at six hours $0.17(95 \%$ CI 0.04 to $0 \cdot 29$ ) 1 , chronic dosing at six hours 0.02 $(95 \%$ CI $-0 \cdot 18$ to $0 \cdot 22) 1$. Slow vital capacity was increased after treatment with salmeterol compared with placebo one and six hours after single but not after chronic dosing. There were no significant differences in static lung volumes or exercise capacity after single or chronic dosing with salmeterol compared with placebo. Patients reported a significantly lower Borg score for perceived exertion following the six minute walk after chronic treatment with salmeterol compared with placebo.

Conclusions - Salmeterol produced a small improvement in spirometric values compared with placebo consistent with the degree of reversibility originally shown by the subjects to salbutamol $200 \mu \mathrm{g}$. This was not associated with improvements in static lung volumes or exercise capacity, but there was some symptomatic benefit in that patients were able to walk the same distance in six minutes with less perceived exertion.

(Thorax 1996;51:689-693)

Keywords: chronic obstructive pulmonary disease, lung function, exercise capacity, salmeterol.

Although the long acting $\beta_{2}$ receptor agonist salmeterol produces prolonged, clinically significant bronchodilatation following both single and chronic dosing in asthmatic subjects, ${ }^{12}$ little information is available regarding the effects of salmeterol on lung function in patients with chronic obstructive pulmonary disease (COPD). Furthermore, when evaluating bronchodilators in this context, in addition to the changes in spirometric parameters that may be expected to be small and of limited clinical significance in themselves, it is also important to consider the impact of the drug on the functional capacity of a patient.

Assessment of exercise capacity in this group of patients does, however, present difficulties. When evaluating exercise capacity in normal subjects an assessment of maximum oxygen consumption is usually made. This, however, requires repeated estimations to ensure adequate consistency of the measurement, and the procedure itself is demanding because it requires exercise to exhaustion which would be both hazardous and impractical in patients with COPD. Attempts have therefore been made to establish reliable indices of performance during submaximal exercise. Spiro et al suggested the concept of physiological strain. ${ }^{3}$ By measuring heart rate and ventilation at relatively low levels of oxygen consumption it is possible to relate the increase in heart rate or ventilation to an estimate of the subject's maximum capacity to increase heart rate or ventilation. This capacity for increase is termed the adaptation capacity. Thus, an individual will be less fit and have a greater physiological strain if a given energy expenditure requires a larger proportion of the adaptation capacity. The primary aim of this study was to evaluate the effect of single and chronic dosing with salmeterol on exercise capacity in patients with COPD. The effects of single and chronic dosing with salmeterol on lung function were also assessed.

Methods

SUBJECTS

Patients with stable COPD with a forced expiratory volume in one second $\left(\mathrm{FEV}_{1}\right)$ of 
$25-75 \%$ of predicted normal and $5-15 \%$ reversibility to salbutamol $200 \mu \mathrm{g}$ were recruited into the study. Patients with other significant systemic or musculoskeletal disease or those requiring maintenance therapy with oral steroids were excluded.

Forty six patients were initially recruited from a respiratory outpatient clinic of whom 29 were randomised to treatment and were therefore included in the intent-to-treat analysis. Reasons for withdrawal prior to randomisation were as follows: ineligibility (three patients), adverse events (three patients), defaulted (four patients), failure to return (six patients), and non-compliance (one patient). All patients gave written informed consent to participate in the study which was approved by the Tayside committee for medical ethics.

The intent-to-treat population consisted of 22 men and seven women with a mean (SE) age of $64(1.5)$ years, $\mathrm{FEV}_{1}$ of $1.18(0.08) 1$, 42 (3) \% of predicted, and $12.5(1.3) \%$ reversibility to salbutamol $200 \mu \mathrm{g}$. All subjects had a history of current or previous tobacco smoking. Concurrent medication during the study was as follows: inhaled corticosteroids (24 patients), theophylline preparations (six), and inhaled anticholinergics (seven). Prior to the run-in period 28 patients were using inhaled $\beta_{2}$ agonists.

Of the 29 patients in the intent-to-treat population, 24 completed the study. Reasons for withdrawal after randomisation to treatment were as follows: adverse events (three patients), ineligibility (one), non-compliance (one), and one patient defaulted.

\section{DESIGN}

The study was of a randomised, double blind, placebo controlled, crossover design with 15 patients being allocated to receive salmeterol followed by placebo, and 14 patients receiving placebo followed by salmeterol. After a run-in period of at least a week during which $\beta_{2}$ agonists other than salbutamol on an as required basis were withdrawn, patients were randomised to receive four weeks of treatment with salmeterol $50 \mu \mathrm{g}$ twice daily (Salmeterol metered dose inhaler, $25 \mu \mathrm{g}$ per actuation, Glaxo Research and Development Ltd, Ware, Hertfordshire, UK) or matching placebo with a one week washout in between.

\section{PROTOCOL}

After the initial screening visit patients visited the laboratory on two occasions during the runin period to familiarise themselves with the exercise protocols. Patients were required to withhold bronchodilators for an appropriate period before each visit to the laboratory - that is, six hours for short acting bronchodilators and 24 hours for theophylline preparations. During each visit spirometric tests, helium static lung volume measurements, six minute walking and cycle ergometry tests were performed. $\mathrm{FEV}_{1}$ and FVC were required to be within $10 \%$ of the values recorded at the initial screening visit.
At the end of the run-in period patients attended the laboratory to receive their first dose of study medication - that is, the randomisation visit. Spirometric tests were performed before the first dose, at regular intervals during the first hour after the first dose, and again six hours after dosing. Static lung volume and gas transfer measurements, six minute walking and cycle ergometry tests were performed one and six hours after the single dose. At the end of the four week treatment period patients attended the laboratory six hours after the final dose of study medication and spirometric tests, static lung function and gas transfer measurements, six minute walking and cycle ergometry tests were then performed. Subjects then had a one week washout period before crossing over to the second treatment period.

\section{MEASUREMENTS \\ Lung function}

Spirometric parameters were measured with a dry wedge spirometer (Vitalograph, Buckinghamshire, UK) according to American Thoracic Society criteria, with the best of three consistent recordings being used in the analysis. ${ }^{4}$ Measurements of static lung volumes and gas transfer were made by closed circuit helium dilution and single breath carbon monoxide techniques, respectively, using a transfer test machine (PK Morgan Ltd, Rainham, Kent, UK).

\section{Exercise tests}

A standardised six minute walking test was performed with heart rate, blood pressure, and oxygen saturation being monitored before and after the walk. In addition, at the end of the walk patients were asked to state Borg scores for perceived exertion, breathlessness, chest pain, and fatigue. ${ }^{5}$ Patients then had a $30 \mathrm{~min}$ ute rest period before commencing a progressive exercise test performed on a bicycle ergometer. During the test, tidal volume, minute ventilation, oxygen uptake, heart rate, blood pressure, and oxygen saturation were recorded. After an initial minute at rest during which baseline values were established, patients were requested to pedal at $50-60 \mathrm{rpm}$ against zero load for a further minute after which a load of $10 \mathrm{~W}$ was introduced. At the end of each subsequent minute the load was increased by $10 \mathrm{~W}$. The test was terminated either at the patient's request or when $80 \%$ of the predicted maximum heart rate was reached. The Borg symptom score was recorded at the end of the test. Values for ventilation and heart rate at oxygen consumption levels of 750 and $1000 \mathrm{ml} /$ min were calculated and used to derive values for physiological strain.

\section{STATISTICAL ANALYSIS}

Analysis of the data was performed using SAS and Statgraphics software packages. Spirometric data, static lung volumes, and cycle ergometry data were analysed using analysis of variance (ANOVA). The six minute walking 
Table 1 Mean spirometric values and static lung volumes one and six hours after a single dose of salmeterol $50 \mu \mathrm{g}$ or placebo, and at six hours after a four week treatment period with salmeterol $50 \mu \mathrm{g}$ twice daily or placebo

\begin{tabular}{|c|c|c|c|c|c|c|c|c|c|}
\hline & \multicolumn{6}{|c|}{ Single dosing } & \multicolumn{3}{|c|}{ Chronic dosing } \\
\hline & \multicolumn{3}{|l|}{1 hour } & \multicolumn{3}{|l|}{6 hours } & \multirow[b]{2}{*}{ Placebo } & \multirow[b]{2}{*}{ Salmeterol } & \multirow[b]{2}{*}{$95 \% C I$} \\
\hline & Placebo & Salmeterol & $95 \% C I$ & Placebo & Salmeterol & $95 \% C I$ & & & \\
\hline $\mathrm{dFEV}_{1}(\mathrm{l})$ & 0.08 & $0 \cdot 14$ & 0.02 to 0.11 & -0.03 & $0 \cdot 13$ & 0.09 to 0.22 & 0.01 & $0 \cdot 12$ & 0.03 to 0.19 \\
\hline $\mathrm{dFVC}(\mathrm{l})$ & $0 \cdot 17$ & $0 \cdot 23$ & -0.08 to 0.20 & 0.03 & $0 \cdot 20$ & 0.04 to 0.29 & $0 \cdot 13$ & $0 \cdot 15$ & -0.18 to 0.22 \\
\hline SVC (l) & $2 \cdot 63$ & $2 \cdot 91$ & 0.17 to 0.39 & $2 \cdot 61$ & $2 \cdot 86$ & 0.13 to 0.37 & $2 \cdot 69$ & $2 \cdot 76$ & -0.12 to 0.26 \\
\hline TLC (l) & $5 \cdot 66$ & $5 \cdot 88$ & -0.12 to 0.56 & $5 \cdot 67$ & $5 \cdot 83$ & -0.06 to 0.39 & $5 \cdot 82$ & $5 \cdot 68$ & $-0 \cdot 38$ to $0 \cdot 1$ \\
\hline $\mathrm{RV}(\mathrm{l})$ & 3.03 & $2 \cdot 96$ & -0.42 to 0.29 & $3 \cdot 06$ & $2 \cdot 97$ & $-0 \cdot 34$ to $0 \cdot 16$ & $3 \cdot 13$ & $2 \cdot 79$ & -0.75 to 0.07 \\
\hline
\end{tabular}

$\mathrm{TLC}=$ total lung capacity; $\mathrm{RV}=$ residual volume; $\mathrm{SVC}=$ slow vital capcity; $\mathrm{dFEV}_{1}=$ change in forced expiratory volume in one second from baseline; $\mathrm{dFVC}=$ change in forced vital capacity from baseline.

Table 2 Changes from resting values in ventilation ( $d V e n t)$, oxygen uptake ( $\left.d \dot{V}_{2}\right)$ and heart rate (dHR), oxygen saturation $\left(\mathrm{dO}_{2}\right)$, and the derived parameters of physiological strain for heart rate and ventilation during bicycle ergometry six hours after a single dose of placebo or salmeterol $50 \mu \mathrm{g}$ and after four weeks of treatment with placebo or salmeterol

\begin{tabular}{|c|c|c|c|c|c|c|}
\hline & \multicolumn{3}{|c|}{ Single dosing } & \multicolumn{3}{|c|}{ Chronic dosing } \\
\hline & Placebo & Salmeterol & $95 \% C I$ & Placebo & Salmeterol & $95 \% C I$ \\
\hline dṾent $(1 / \mathrm{min})$ & $18 \cdot 33$ & $17 \cdot 65$ & $-3 \cdot 17$ to $1 \cdot 81$ & $17 \cdot 84$ & 18.99 & -0.5 to $2 \cdot 8$ \\
\hline $\mathrm{dVO} \mathrm{O}_{2}(\mathrm{ml} / \mathrm{min})$ & 657 & 609 & -141 to 45 & 623 & 640 & -89 to 123 \\
\hline $\mathrm{dHR}$ (beats/min) & 43 & 42 & -12 to 19 & 41 & 44 & -7 to 13 \\
\hline $\mathrm{do}_{2}$ sat $(\%)$ & -1 & -1 & -1 to 1 & -1 & -1 & -1 to 1 \\
\hline Physiological strain [HR](\%) & 73.9 & $73 \cdot 3$ & -33.5 to 32.3 & $77 \cdot 1$ & $69 \cdot 9$ & -33 to $18 \cdot 8$ \\
\hline Physiological strain [Vent] $(\%)$ & $63 \cdot 5$ & $58 \cdot 3$ & -16.3 to 5.8 & $64 \cdot 6$ & $64 \cdot 5$ & -8.4 to $8 \cdot 2$ \\
\hline
\end{tabular}

test and Borg symptom scores were analysed non-parametrically using Koch's analysis. Changes in $\mathrm{FEV}_{1}$ and FVC from baseline following treatment were analysed using the ordinary least squares method of analysis. A p value of $<0.05$ was taken to be of significance for all tests. The number of subjects with increases in $\mathrm{FEV}_{1}$ and $\mathrm{FVC}$ of greater than $160 \mathrm{ml}$ and $330 \mathrm{ml}$, respectively, after single and chronic dosing with salmeterol was also recorded. These criteria have previously been used to define patients with COPD who have a response to bronchodilators greater than that which could be attributed to natural variability. ${ }^{6}$

\section{Results}

SPIROMETRIC PARAMETERS

There was no significant difference in mean (SE) baseline values before treatment with placebo or salmeterol: $\mathrm{FEV}_{1}, 1 \cdot 17(0.08) 1$ in the placebo group and $1.17(0.08) 1$ in the salmeterol group; FVC, $2.05(0.11) 1$ in the placebo group and $2 \cdot 19(0 \cdot 12) 1$ in the salmeterol group. Salmeterol produced a small but statistically significant $(p<0.05)$ increase in $\mathrm{FEV}_{1}$ compared with placebo both one and six hours after single dosing, and this was maintained after chronic dosing. The increase in FVC was significantly greater following salmeterol than with placebo six hours after single but not chronic dosing. Slow vital capacity was increased after treatment with salmeterol compared with placebo one and six hours after single but not chronic dosing (table 1, figure).

Of the 24 patients who completed the study eight were defined as bronchodilator responders with an increase in $\mathrm{FEV}_{1}$ of $>160 \mathrm{ml}$ after a single dose of salmeterol, and seven patients fulfilled the criteria after chronic dosing with five fulfilling the criteria after both single and chronic dosing. With regard to FVC, nine patients had an increase of $>330 \mathrm{ml}$ after a single dose of salmeterol which was maintained in six after chronic dosing; five patients showed the increase after both single and chronic dosing. Only two patients showed a persistent improvement in both $\mathrm{FEV}_{1}$ and FVC.

\section{STATIC LUNG VOLUMES}

There were no significant differences in static lung volumes following single or chronic dosing with salmeterol or with placebo (table 1).

\section{SIX MINUTE WALKING TEST}

There was no significant increase in the distance walked six hours after single or chronic dosing with salmeterol compared with placebo. The median (interquartile range) values following a single dose were 450 (371-491) $\mathrm{m}$ for placebo and 456 (390-473) $\mathrm{m}$ for salmeterol, and following chronic dosing the results were 450 (371-491) $\mathrm{m}$ for placebo and 425 (392-473) $\mathrm{m}$ for salmeterol. Borg scores for perceived exertion were significantly lower with salmeterol than with placebo after chronic $(\mathrm{p}=$ $0.004)$ but not single dosing $(p=0.06)$, with median (interquartile range) values following single dosing of $0.5(0-1)$ for placebo and 1 (0-2) for salmeterol, and following chronic dosing $1(0-2)$ for placebo and $0.5(0-1)$ for salmeterol.

\section{BICYCLE ERGOMETRY}

There were no significant differences in oxygen uptake, ventilation, and heart rate responses or oxygen saturation during exercise following treatment with salmeterol or placebo. In addition, there were no significant differences in derived variables of physiological strain for heart rate and ventilation after treatment with salmeterol or placebo. Treatment with salmeterol was not associated with a reduction in Borg scores following bicycle ergometry compared with placebo (table 2). 

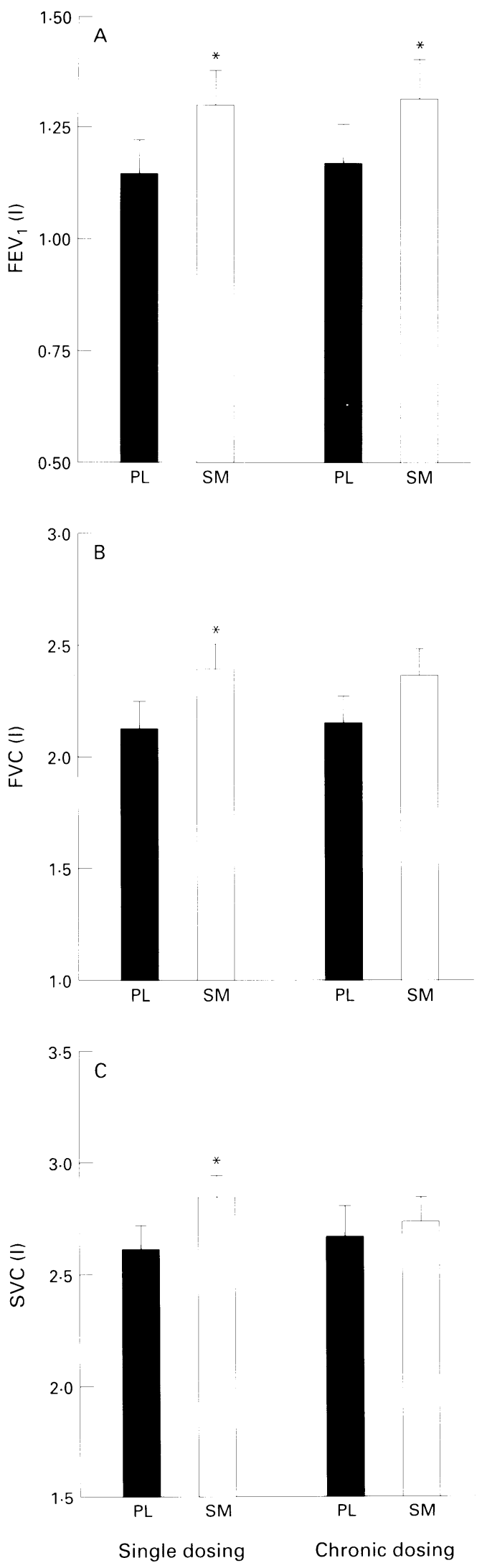

Mean (SE) values of (A) $F E V_{1}$, (B) $F V C$, and (C) slow vital capacity (SVC) six hours after a single dose of salmeterol $50 \mu \mathrm{g}(S M)$ or placebo $(P L)$ and after four weeks of treatment with salmeterol $50 \mu \mathrm{g}$ twice daily or placebo. ${ }^{*} p<0 \cdot 05$ versus placebo.

\section{Discussion}

The results of this study show that salmeterol produced a small but statistically significant improvement in $\mathrm{FEV}_{1}$ compared with placebo after both single and chronic dosing. This was associated with an improvement in FVC and SVC after single but not chronic dosing. In terms of exercise performance, neither single nor chronic dosing produced significant improvement. Following chronic dosing, however, Borg scores for perceived exertion after the six minute walking test were significantly lower with salmeterol than with placebo.

The benefits of long acting $\beta_{2}$ agonists in terms of improving lung function, exercise capacity, or symptoms in patients with relatively fixed airways obstruction has not yet been established. The available evidence regarding the benefits of short acting $\beta_{2}$ agonists in this regard is, however, conflicting. Both single and chronic dosing with conventional and high doses of $\beta_{2}$ agonists have been shown in some studies to improve spirometric values, walking distance, and symptom scores in patients with relatively fixed airways obstruction. ${ }^{71}$ Other studies in apparently comparable patient groups have, however, reported no significant improvement in lung function or exercise performance. ${ }^{1213} \mathrm{It}$ has also been noted that symptoms can appear to improve without significant measurable improvement in lung function or exercise performance. ${ }^{1314}$ It is difficult, however, to compare these studies directly as there were differences in patient selection criteria, particularly with regard to the measures taken to exclude a significant reversible component to the airway obstruction. Variations in sample size, and hence the power of the study, and in the doses of bronchodilator used may also have influenced the results.

In the present study patients with a mean reversibility of $12.5 \%$ to salbutamol $200 \mu \mathrm{g}$ were selected. This dose of salbutamol has been found to be of equivalent bronchodilator efficacy in asthmatic subjects to $50 \mu \mathrm{g}$ of salmeterol. ${ }^{1}$ The finding of a mean improvement in $\mathrm{FEV}_{1}$ of $12 \%$ in this group of patients following treatment with salmeterol $50 \mu \mathrm{g}$ is therefore consistent with the inclusion criteria for this study. It is worth noting that this mean value encompasses a wide range of individual responses with some responses small enough to be attributable to natural variability, whilst in a few subjects increases in $\mathrm{FEV}_{1}$ and FVC were large enough to exclude natural variability with confidence. ${ }^{6}$ It is possible that higher than conventional doses may have produced additional benefit in terms of bronchodilation as has been shown with $\beta_{2}$ agonists such as salbutamol and terbutaline. ${ }^{1015}$

In this study two tests were used to measure different aspects of exercise capacity. The walking test is a self paced measurement, using a familiar form of exercise, and therefore may be influenced by factors other than pulmonary function including the attitude and motivation of a particular patient. These factors have, in fact, been shown to be better predictors of performance on this test than measures of $\mathrm{FEV}_{1}$ and FVC. ${ }^{16}$ Cycle ergometry follows a set pace using a less familiar form of exercise. It does, however, permit more complex physiological monitoring. Both forms of exercise test are subject to training effects with repeated testing. ${ }^{17}$ In the present study the use of two tests 
during the run-in period and the crossover design of the study would, however, have minimised the influence of such an effect on the results. In patients with COPD exercise limitation may be due to a combination of abnormalities including abnormalities of ventilatory mechanics, respiratory muscles, alveolar gas exchange and cardiac function. ${ }^{18}$ Alterations in ventilatory mechanics provide one of the most important limitations to exercise performance. Expiratory airflow obstruction is the main pathophysiological consequence of the underlying disease and, as a result, resting expiratory airflows in the patients in this study would be near to their achievable maximum. The prolongation of expiration together with the increased breathing rate during exercise will lead to hyperinflation and consequently an increase in the work of breathing. Thus, it could be predicted that relieving some of the expiratory obstruction may improve pulmonary mechanics by enabling breathing at a lower residual volume and therefore exercise capacity. In this study the small improvements in spirometric values were not, however, associated with an improvement in exercise capacity. This is perhaps not surprising given that "gas trapping" measured at rest was not significantly improved either in terms of a reduction in residual volume or the ratio of residual volume to total lung capacity.

From a practical point of view this study suggests that relatively complex exercise testing does not provide any additional useful information in terms of detecting clinically relevant improvements compared with more straightforward tests of lung function and six minute walking distance. With the exception of the Borg symptom scores following the six minute walking test, the responses were consistent after both single dosing and a period of regular treatment.

The symptomatic improvement which allows a comparable distance to be walked in six minutes with less perceived exertion after chronic dosing with salmeterol may represent a significant benefit to these patients in whom treatment options are relatively limited. In this regard a more detailed assessment of functional capacity and quality of life may have provided further evidence of benefit from treatment with salmeterol, as observed in a recent study which evaluated the effects of chronic dosing with salmeterol or placebo on quality of life in patients with COPD. ${ }^{19}$

We would like to thank Glaxo Research and Development Ltd for their support of this study.

1 Ullman A, Svedmyr N. Salmeterol, a new long-acting inhaled beta- 2 adrenoceptor agonist: comparison with salhaled beta-2 adrenoceptor agonist: comparison with sal-
butamol in adult asthmatic patients. Thorax 1988;43: butamol

2 Dahl R, Earnshaw JS, Palmer JBD. Salmeterol: a four-week study of a long-acting beta-adrenoceptor agonist for the treatment of reversible airways disease. Eur Respir f 1991; 4:1178-84.

3 Spiro SG, Juniper E, Bowman P, Edwards RHT. An increasing work rate test for assessing the physiological strain of submaximal exercise. Clin Sci Mol Med 1974;46: 191-206.

4 American Thoracic Society. Standardisation of spirometry - 1987 update. Am Rev Respir Dis 1987;136:1285-98.

5 Borg G. Perceived exertion as an indicator of somatic stress. Scand f Rehab Med 1970;2-3:92-8.

6 Tweedale PM, Alexander F, McHardy GJR. Short term variability in $\mathrm{FEV}_{1}$ and bronchodilator responsiveness in patients with obstructive ventilatory defects. Thorax 1987 42:487-9.

7 Guyatt GH,Townsend M, Pugsley SO, Keller JL, Short $\mathrm{DH}$, Taylor DW, et al. Bronchodilators in chronic airflow limitation. Effects on airway function, exercise capacity and quality of life. Am Rev Respir Dis 1987;135:1069-74.

8 Connellan SJ, Gough SE. The effects of nebulised salbutamol on lung function and exercise tolerance in patients with severe airflow obstruction. Br $\mathcal{F}$ Dis Chest 1982;76: 135-42.

9 Bellamy D, Hutchison DCS. The effects of salbutamol aerosol on lung function in patients with pulmonary emphysema. Br f Dis Chest 1981;75:190-6.

10 Corris PA, Neville E, Noriman S, Gibson GJ. Dose-response study of salbutamol powder in chronic airflow obstruction. Thorax 1983;38:292-6.

11 Lipworth BJ, Clark RA, Dhillon DP, McDevitt DG. Comparison of the effects of prolonged treatment with low and high doses of inhaled terbutaline on beta-adrenoceptor responsiveness in patients with chronic obstructive pulmonary disease. Am Rev Respir Dis 1990;142:338-42.

12 Taylor DR, Buick B, Kinney C, Lowry RC, McDevitt DG. The efficacy of orally administered theophylline, inhaled salbutamol, and a combination of the two as chronic therapy in the management of chronic bronchitis with reversible airflow obstruction. Am Rev Respir Dis 1985; 131:747-57.

13 Evald T, Keittelman S, Sindrup JH, Lange P. The effect of inhaled terbutaline on $\mathrm{FEV}_{1}, \mathrm{FVC}$, dyspnoea and walking distance in patients with chronic obstructive lung disease. Respir Med 1992;86:93-6.

14 Berger R, Smith D. Effects of inhaled metaproterenol on exercise performance in patients with stable fixed airway obstruction. Am Rev Respir Dis 1988;138:624-9.

15 Newnham DM, Dhillon DP, Winter JH, Jackson CM, Clark RA, Lipworth BJ. Bronchodilator reversibility to low and high doses of terbutaline and ipratropium bromide in patients with chronic obstructive airways disease. Thorax patients with chronic

16 Morgan AP, Peak DF, Buchanan DR, McHardy GJR. Effects of attitudes and beliefs on exercise tolerance in chronic bronchitis. $B M F$ 1983;286:171-3.

17 Swinburn CR, Wakefield JM, Jones PW. Performance, ventilation and oxygen consumption in three different types of exercise test in patients with chronic obstructive lung disease. Thorax 1985;40:581-6.

18 Belman MJ. Exercise in patients with chronic obstructive pulmonary disease. Pulmonary rehabilitation in chronic respiratory insufficiency. Thorax 1993;48:936-46.

19 Jones PW, Bosh TK. Improvement in quality of life in COPD patients treated with salmeterol. Am $\mathcal{F}$ Respir Crit Care Med 1995;151:A464. 